\title{
GP use of psychotherapy services
}

\author{
MARY J. MORTON, Senior Registrar in Psychotherapy, Leicestershire Department of \\ Psychotherapy, Humberstone Grange Clinic, Thurmaston Lane, Leicester LE5 0TA; \\ and Jill StaINES, Senior Registrar in Psychotherapy, Nottingham Psychotherapy \\ Department, St Ann's House, 114 Thorneywood Mount, Nottingham NG3 2PZ
}

In a rapidly changing NHS, there is a great awareness of the need to consult with general practitioners about their expectations of a service. A number of studies have looked at GPs' perceptions of psychological and psychiatric services (e.g. Eastman \& McPherson, 1982; Whitfield \& Winter, 1980) but to date little is known about how GPs view psychotherapy services. About $40 \%$ of the referrals to the Leicestershire psychotherapy department come directly from GPs and the present study aimed to ascertain local GPs' perceptions of the service. This was timely for the purpose of planning local development but clearly has important implications for psychotherapy services in general.

\section{The study}

The Leicester psychotherapy department provides a psychodynamic psychotherapy service for the county of Leicestershire (population approximately $900,000)$. Based in Leicester city, a range of therapies and training opportunities are provided. It is a small department for such a population and hence the waiting list for treatment is long, with patients having to wait up to 18 months for long-term individual therapy (following initial assessment).

The need for an expansion of the service has been acknowledged, and so in the context of plans for new developments a questionnaire was sent to all the GPs (78) in one of the Leicestershire catchment areas Charnwood district, with follow-up visits to a selection of practices. Charnwood district (population $145,000)$ is in the north of the county and the town of Loughborough is its main centre.

The questionnaires were sent in January 1992 and the six practices (30 GPs) were visited in May-June 1992. Three of the practices were in Loughborough and the other three in outlying parts of the Charnwood area. The practices were chosen to represent the views of both fundholding and non-fundholding GPs.

A number of areas were addressed in the questionnaire and follow-up visits:

(a) GPs' awareness of and previous use of the service (b) their estimate of need for the service, i.e. how many patients they perceived as needing referral in one year

(c) their satisfaction with the service and any deterrants to referral

(d) the availability of alternative resources

(e) the question of whether fundholding status might alter the use of a psychotherapy service.

\section{Findings}

There was a high response rate to the questionnaire, with 66 out of the 78 GPs responding (83\%). They unanimously agreed about the necessity of a psychotherapy service, although were sometimes unclear about whom to refer. Awareness of the clinical aspects of the service was high, although eight GPs had not known we existed. Only seven GPs were aware of training opportunities offered. Most GPs $(80 \%)$ had had previous contact with the department. It was difficult to make an assessment of the estimated need for a psychotherapy service, answers varying from two to 50 referrals per year with a median of five. This difficulty is addressed in the discussion below.

The main source of dissatisfaction was the length of the waiting list, with 47 GPs citing this as a deterrent to referral. Fifteen GPs also mentioned the need for a locally based service.

When GPs were asked about alternative resources, community mental health teams and private counsellors were mentioned, although 14 GPs felt that they had no alternatives to turn to for many patients with long-term psychological difficulties.

Regarding fundholding status, $75 \%$ felt that it would not affect the use of a psychotherapy service. Forty-one GPs were either fundholding already, or about to become fundholders and of this group, $73 \%$ anticipated no change in their use of a service, with a further $20 \%$ predicting an increased use.

\section{Comments}

This study is a local one but with $83 \%$ of the GPs in the area responding to our questionnaire, a wide range of views is represented. The views expressed in 
the follow-up visits were similar to the questionnaire answers, thus validating the latter.

There was a clear message that a specialist psychotherapy service was seen as an essential resource for GPs, and one that needed to be based locally. The GPs recognised a great unmet need for psychotherapy within their patient population and wanted direct access to the service. The length of the waiting list was seen as the biggest deterrent to referral and available alternative resources were few.

\section{Estimate of need}

The question of estimated need is a complex one, and the great variation between GPs is an indication of this. An estimated referral rate varying from 1-50 per year suggests that more than one group of patients is represented. In considering this, it is useful to refer to the three levels of psychotherapy training and practice delineated by Professor Cawley at the Association of University Teachers of Psychotherapy Conference in 1976 and elaborated by Dr J. Pedder (1989). Different groups of patients are most appropriately treated at each level.

Level 1 represents the psychotherapy and counselling that can be provided within a primary care setting. Patients suffering from emotional distress, following painful life events such as bereavement are best treated in this setting by a member of the primary care team. They do not require psychiatric referrral.

Level 2 refers to the psychotherapy provided by the mental health team, who should have acquired some specialist psychotherapy skills as part of their overall training. Here, psychotherapy is an important part of a comprehensive treatment plan, which might include other components (eg. social support, medication). These patients often have complex psychosocial difficulties requiring a range of support and treatment, including psychotherapy.

Level 3 represents the psychotherapy provided within a specialist psychotherapy department, by career psychotherapists with intensive training. Patients treated in this setting suffer from affective, neurotic and personality disorders; they have long-standing emotional difficulties which usually relate to early deprivation. Treatment aims, both to relieve present symptomatology, and to resolve the underlying causes of distress. It will often be long term.

It is not always clear which setting and treatment be appropriate for a particular patient. When GPs estimate a referral rate of 50 patients per year to the psychotherapy service, they might be including patients who could more appropriately be treated by a GP counsellor in a primary care setting. This subject merits further investigation. However, there are resource implications for a specialist psychotherapy service at all levels of psychotherapy provision. The role of such a service is not only to provide level 3 psychotherapy but to offer training opportunities and supervision for those providing level 2 and perhaps also reach out to the primary care team involved at level 1 provision.

At a local level, we learnt a lot from this study and plan to develop peripherally rather than expanding the central department. We think that this request for a local service is likely to be echoed by GPs throughout the country.

The discussions we have had raise many further questions for both GPs and psychotherapy services in general. There is a great need for further study and a continuing dialogue between GPs and psychotherapy services throughout the country, which will hopefully improve provision overall. A final word: our experience of this process has been heartening psychotherapy services are wanted and valued. With this as 'a secure base', we can learn a lot from our GP colleagues and collaboratively plan for the future.

\section{Acknowledgements}

We wish to thank Dr Chris Whyte, Consultant Psychotherapist, for his comments and also all the GPs participating in the study.

\section{References}

Eastman, C. \& McPherson, I. (1982) As others see us: general practitioners' perceptions of psychological problems and the relevance of clinical psychology. British Journal of Clinical Psychology, 21, 85-92.

PEDDER, J. R. (1989) Courses in psychotherapy. Evolution and current trends. British Journal of Psychotherapy, 6, 203-221.

Whitfield, M. J. \& WINTER, R. D. (1980) Psychiatry and general practice: results of a survey of Avon general practitioners. Journal of the Royal College of General Practitioners, 30, 682-686. 